\title{
The pharmacologic management of depression in Parkinson's disease
}

\section{Matthew A Schreiber Alexander W Thompson}

University of Washington, Department of Psychiatry and Behavioral Sciences, Seattle, WA, USA

Correspondence: Alexander W Thompson

University of Washington, Harborview Medical Center, 325 Ninth Ave; Box 359896, Seattle, WA 98104-2499, USA

Tel +2067449427

Fax +206744 4427

Email awthomp@uw.edu
This article was published in the following Dove Press journal:

Degenerative Neurological and Neuromuscular Disease

17 January 2013

Number of times this article has been viewed

\begin{abstract}
Depression in Parkinson's disease (PD) is common, and it appears to worsen the motor and cognitive progression of the disease, and limits the patient's quality of life. In this paper, we review the pharmacotherapy of depression in people with PD. We find that evidence is sparse when it comes to this patient population. There is some evidence that older tricyclic antidepressants (nortriptyline and desipramine) may be effective in this population. There is also growing evidence that newer antidepressants like paroxetine and venlafaxine may be effective. We will also review a number of other promising medication treatments. What is apparent is the need for more research identifying the most effective medications for treating depression in this population. We provide recommendations that fall in line with current evidence-based practice for managing depression in the general population. Also, we suggest that collaborative models of depression care may be a promising approach to support the identification and effective treatment of those with PD also suffering from depressive disorders.
\end{abstract}

Keywords: pharmacotherapy, collaborative care, Geriatric Depression Scale, neurology

\section{Introduction}

Parkinson's disease (PD) is a common, progressive neurodegenerative disease. ${ }^{1}$ Since the main risk factor for idiopathic PD is age, an inexorable increase in the number of patients with PD is expected in the immediate future, posing a significant public health burden. Moreover, PD has a chronic, degenerative, and unpredictable course, posing substantial challenges for patients, caregivers, and clinicians.

Apart from the hallmark motor symptom triad of bradykinesia, rigidity, and tremors, PD has substantial nonmotor complications, one of the most common of which is depression. Depression in PD (DPD) is itself the subject of intensive research and poses significant challenges to the clinician and researcher alike, and the understanding of DPD is evolving even as our understanding of PD advances, as noted in an excellent recent comprehensive review. ${ }^{2}$ Despite uncertainties about the etiology and phenomenology of mood symptoms in PD, it is well established that depressive symptoms are exceedingly common in PD. ${ }^{3,4}$ For this reason, it is valuable for neurologists, psychiatrists, internists, and allied health professionals to be aware of the complexity of identifying DPD and, in turn, the uncertainties surrounding its treatment. Fortunately, there is much ongoing research addressing this problem, and an increasing body of evidence guiding clinicians.

In this review, we focus on the most relevant aspects of DPD for practicing clinicians. First, we provide an overview of the current state of evidence-based treatment for DPD. We then address the inherent diagnostic and therapeutic challenges facing clinicians 
caring for those with depression and PD. Finally, we propose that collaborative models of care (founded in the Chronic Care Model), ${ }^{5}$ the evidence-based standard for managing common mental health problems in those with medical illness, offers much hope in improving the care of those with $\mathrm{PD}$ and depression compared to care as usual.

\section{Depression in Parkinson's disease: an overview}

Major depression, as defined currently by the Diagnostic and Statistical Manual (DSM)-IV-TR, ${ }^{6}$ has been described in people for thousands of years. It is an illness with characteristic signs and symptoms, and a growing list of evidence-based treatments. The syndrome of major depression is commonly seen in those with PD and appears to be associated with increased disability and a decreased quality of life. ${ }^{7,8}$ Despite this, major depression in those with PD is challenging to study. There is substantial symptom overlap between the two conditions, leaving clinicians to face the quandary of "is this PD, or does this patient have a depressive disorder?" The answer is important because depression treatments may not be benign, especially in medically complex patients such as elderly PD patients who have significant comorbidities. In addition, it remains a substantially open question whether the syndrome of depression in someone with PD may be pathophysiologically different than the major depressive disorders seen in those with no other medical problems. Below we explore these ideas further in considering recommendations for treating DPD.

\section{Depression in Parkinson's disease is common and disabling}

Despite these challenges, there is compelling evidence from extensively replicated, detailed studies showing that the rates of depressive symptoms are significantly and substantially increased in PD, even when taking into account these complicating factors. Because depression is a clinical diagnosis, estimates of prevalence critically depend on how depression is defined and measured - an issue that has also affected the ability to carry out large-scale clinical trials. Prevalence estimates have varied widely, from seven to seventy percent. ${ }^{3,4}$ In a systematic review, it was found that the weighted prevalence of major depression was $17 \%$, while minor depression and dysthymia affected an additional $22 \%$ and $13 \%$ of PD patients, respectively. ${ }^{3}$ These rates may be even higher in PD complicated by dementia, where depressive symptoms were present in $77 \%$ of a large $(\mathrm{N}=537)$ sample. ${ }^{9}$ It has been noted that beyond an elevated incidence of major depression, as formally diagnosed using DSM-IV-TR criteria, there also is a high rate of depressive symptoms at a subsyndromal level in PD. ${ }^{10}$

In addition to being a relatively common nonmotor complication of PD, DPD imposes a significant functional burden on patients with $\mathrm{PD}$, reducing their quality of life beyond that due to PD itself. ${ }^{11}$ The negative effect depression has on quality of life appears to be more pronounced in younger-onset PD patients, ${ }^{12}$ though this has not yet been shown to be linked to any specific molecular lesion. ${ }^{13}$ Depressive symptoms also increase the stress on caregivers. ${ }^{14}$ An additional reason to be vigilant about DPD is that while suicide has not been shown to be a very common end for those with $\mathrm{PD}$, rates of suicidal ideation are increased in PD, likely contributing to the reduction in quality of life. ${ }^{15}$ Even in the absence of large numbers of completed suicides, suicidal ideation must remain an important clinical focus.

\section{Depression in Parkinson's disease can be hard to diagnose}

As with a major depressive disorder, PD is a clinical diagnosis. While classic PD, like syndromic major depression, is wellrecognized by trained clinicians, in milder or more complex forms, it can be hard to identify. The symptoms of PD overlap with many of the somatic symptoms of depression; bradykinesia may be interpreted as apathy, masklike faces as affective blunting, or sadness and "off" motor periods as psychomotor retardation. Because of these complexities in diagnosis, a National Institute of Neurological Disorder and Stroke/National Institute of Mental Health panel has recommended that depression be diagnosed inclusively, without undue concern for the potential overlap in symptoms of PD and depression, and that subsyndromal depressions not meeting DSM-IV-TR criteria be addressed and evaluated clinically, despite not fully meeting the criteria for depression. ${ }^{16}$

Identifying DPD in patients is challenging but essential; ${ }^{17}$ to systematize this identification, depression scales have been studied for use in PD, and have been shown to correlate well with clinical diagnoses of depression. ${ }^{18}$ Validation has been essential because DPD may differ phenomenologically from depressive symptoms in the general population. Moreover, validating specific scales for broad use would both increase the comparability of research studies, and aid in developing treatment recommendations and performance measures for clinical treatments. ${ }^{19}$ In a recent study comparing nine scales to detect DPD, the Geriatric Depression Scale (GDS) ${ }^{20}$ was recommended due to its relative ease of use, psychometric properties, and being freely available as it is not copyrighted. ${ }^{21}$ 
In the GDS-30 format - a simple, 30-item questionnaire that patients fill out themselves, with a cutoff score of 9/10 - was found to have the most discriminant value. ${ }^{22}$ The even easier to use GDS-15 was found to have high sensitivity and good positive predictive value when assessed specifically for use in diagnostically validated DPD. The GDS-15 may be most optimal because it is less dependent on physical symptoms, which may overlap with symptoms of PD itself, and which are commonly represented in other scales for depressive symptoms used in the general population. ${ }^{23}$

\section{Depression in Parkinson's disease: pathophysiologically different than major depression?}

In addition to the complexity of diagnosing DPD, there is active research assessing the question of how the pathophysiology of PD may contribute to depression-like symptoms. The theoretical basis for this rests on the destruction of biogenic amine pathways in PD - both on its prototypical effects on the dopaminergic system, and also on the noradrenergic and serotonergic systems strongly implicated in major depression. This debate extends well beyond the world of basic research, since it has an impact on treatment approaches. If depression in $\mathrm{PD}$ is physiologically distinct from depression in otherwise healthy populations (where it is typically studied), it may demand different treatment approaches.

\section{Pharmacotherapy of depression in Parkinson's disease Overview}

Clinical researchers have experienced challenges conducting large, powerful studies of treatments for DPD. In part, this has been due to the heterogeneity and lack of a firm definition of what constitutes DPD. However, as noted below, there has been significant progress recently, and as issues in identifying homogeneous populations of DPD progress, further progress can be expected in the near future.

Since 2003, there have been several expert reviews of DPD treatment, and each of these has noted the paucity of large, randomized, placebo-controlled, double blind studies. At the same time, there have been considerable numbers of case reports and smaller scale studies that have helped inform the direction of the larger studies that have been conducted..$^{25,29,31}$ In the absence of a robust evidence base, clinicians confronted with DPD employ treatments validated in those unaffected by PD. ${ }^{24}$ Prescribing trends have followed those in the general community, with selective serotonin reuptake inhibitors (SSRIs) having greatly eclipsed the use of tricyclic antidepressants (TCAs). ${ }^{24}$ This suggests that prescribers proceed based on the assumption that DPD is similar to major depression in general, and that treatment proceeds (according to the standard principles) with an antidepressant choice that is based on safety and side effect profiles.

Other antidepressants have been studied less often than SSRIs and TCAs, but they are used clinically and would warrant further systematic study, as noted below.

Based on our review of the literature below and our clinical opinion and practice, we have compiled Table 1 and Figure 1. Table 1 summarizes the reviewed medication treatments for DPD and the evidence base supporting each medication class. Figure 1 demonstrates our clinical approach to the medication management of DPD.

\section{Literature reviews of pharmacotherapy for depression in Parkinson's disease}

In 2003, a Cochrane Collaboration review concluded that there was "insufficient data" on the effectiveness and safety of any antidepressant therapies in PD, and that large scale randomized controlled trials were urgently needed. ${ }^{25}$ At that time, they identified only three studies meeting criteria for inclusion, and these three studies were in themselves less than optimal and equivocal in their results. For example, a 1980 study compared nortriptyline to placebo for DPD. ${ }^{26}$ Depression was assessed using a custom scale. The researchers found placebo to be more effective than the antidepressant. ${ }^{26} \mathrm{~A}$ second study compared citalopram with placebo. ${ }^{27}$ Although citalopram

Table I Categories of pharmacotherapy for treating DPD

\begin{tabular}{|c|c|c|c|}
\hline $\begin{array}{l}\text { Drug } \\
\text { category }\end{array}$ & $\begin{array}{l}\text { Mechanism } \\
\text { of action }\end{array}$ & $\begin{array}{l}\text { Representative } \\
\text { drug }^{\mathrm{a}}\end{array}$ & $\begin{array}{l}\text { Support } \\
\text { in DPD }\end{array}$ \\
\hline SSRI & $\begin{array}{l}\text { Selective serotonin } \\
\text { reuptake inhibitor }\end{array}$ & Paroxetine & +++ \\
\hline SNRI & $\begin{array}{l}\text { Serotonin/NE } \\
\text { reuptake inhibitor }\end{array}$ & Venlafaxine & +++ \\
\hline DA agonist & D2 receptor agonist & Pramipexole & +++ \\
\hline Tricyclic & Similar to SNRI & Nortriptyline & ++ \\
\hline MAOI & $\begin{array}{l}\text { Monoamine oxidase } \\
\text { inhibitor }\end{array}$ & Selegiline & + \\
\hline Omega-3 FA & Under investigation & Fish oil & + \\
\hline NDRI & $\begin{array}{l}\text { NE/DA reuptake } \\
\text { inhibitor }\end{array}$ & Bupropion & - \\
\hline
\end{tabular}

Notes: aFor each class, the example medication listed has the most relevance for the treatment of depression in PD, though there may be others in the same class that have not been specifically tested in PD; bsupport in PD reflects the judgment of the authors as a summary of the available literature.

Abbreviations: DPD, depression in Parkinson's disease; SSRI, selective serotonin reuptake inhibitor; SNRI, serotonin/norepinephrine reuptake inhibitor; DA, dopamine; MAOI, monoamine oxidase inhibitor; FA, fatty acids; NDRI, norepinephrine/dopamine reuptake inhibitor; NE, norepinephrine; DA, dopamine. 

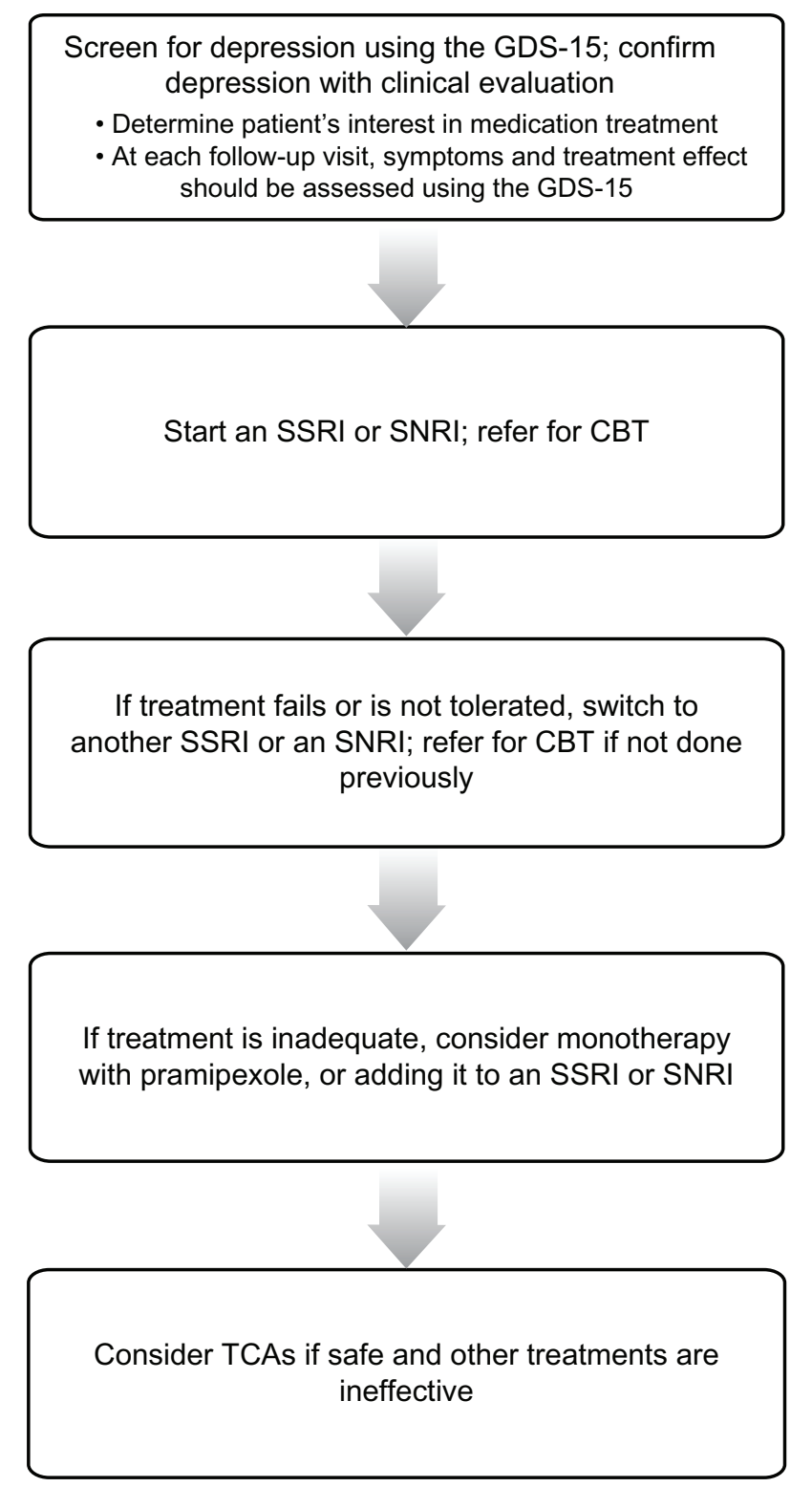

Figure I Our approach to the medication management of DPD.

Abbreviations: DPD, depression in Parkinson's disease; GDS-15, Geriatric Depression Scale-15; SSRI, selective serotonin reuptake inhibitor; SNRI, serotoninnorepinephrine reuptake inhibitor; CBT, cognitive-behavioral therapy; TCA, tricyclic antidepressant.

was well-tolerated and did not appear to worsen PD motor symptoms, there was not a significant difference in depression response between the two treatment groups. A third study considered was only published in abstract form, ${ }^{28}$ making its full interpretation problematic.

Practice parameters from the American Academy of Neurology in 2006 could make only a recommendation for the use of amitriptyline, a TCA, with Level C evidence. ${ }^{29}$ It noted that the absence of evidence for other treatments did not imply an absence of efficacy. A meta-analysis of available studies meeting moderately stringent criteria found a very limited number of studies available, which were not generally supportive of the use of antidepressants. ${ }^{30}$ There was a limited evidence base to support the use of TCAs. A systematic review and meta-analysis concluded that, while evidence did not support the use of SSRIs for DPD, studies were underpowered to disprove the null hypothesis that antidepressants were not effective, and, overall, the studies to date were not conclusive. ${ }^{30}$

More recently, the Movement Disorder Society (MDS) Evidence-Based Medicine Review concluded that the TCAs nortriptyline and despiramine were "likely efficacious" and therefore "possibly useful;" however, it did not find sufficient evidence to recommend such support for SSRIs, so they still had to be classified as investigational. ${ }^{31}$ The dopamine agonist, pramipexole, was judged to be the only well-validated treatment available. Echoing the authors of the Cochrane review, this expert review underlined the imperative need for Class 1 studies of DPD treatment (ie, double-blind, placebo controlled trials) and emphasized the need for caution in treating this population given the remaining uncertainties. ${ }^{31}$

Fortunately, this work is moving forward as seen in the recent multisite, randomized, double-blind, placebocontrolled trial comparing paroxetine, venlafaxine $\mathrm{XR}$, and placebo for people with PD and major depression or subsyndromal depression, as defined by DSM-IV criteria. Both medications showed significant benefits compared to placebo, and neither appeared to worsen motor symptoms. ${ }^{32}$

The following sections include previous recommendations from these expert reviews, and incorporate newer pharmacological findings as well as suggest potential agents for further study outside the dominant classes of antidepressants.

\section{Tricyclic antidepressants (TCAs)}

TCAs were the mainstay of treatment for depression prior to the introduction of SSRIs in the 1980s. They were wellestablished to have clinical efficacy in treating syndromic depression in physically healthy populations, but their effectiveness in PD has also been shown in a small number of controlled studies. ${ }^{33,36}$ However, TCAs pose several clinical difficulties that make them less than preferable for clinical use as a first-line agent for depression (although they were used very successfully for many years in medically healthy, depressed patients). In particular, their side effect profile is unfavorable; anticholinergic side effects can be a burden to the patient, and it can also increase the risk of delirium in this vulnerable population. Moreover, antiadrenergic properties may also prove unacceptable in $\mathrm{PD}$, which carries its own 
risk of dysautonomia, and orthostasis may pose the most significant problem in this population. It should also be noted that TCAs have a relatively low therapeutic index, meaning that their potential lethality in overdose is far greater than comparably effective newer medications, as shown in non-PD study samples.

While the MDS recommends TCA use based on a strict adherence to treatment supported by research evidence, TCAs are likely not as practical in the everyday clinical setting as are the newer and safer to use antidepressants. At the same time, although not yet studied, TCAs may remain effective alternatives to consider in treatment resistant DPD, and they must be kept in mind as a treatment option by clinicians caring for those with DPD. ${ }^{37}$ Also, an exciting recent study suggested that TCA treatment may delay the progress of the disease by noting that those with early-onset PD who were taking TCAs had a delayed need to start dopaminergic (DA) therapy for motor symptoms. ${ }^{38}$

\section{Selective serotonin reuptake inhibitors (SSRIs) and serotonin/norepinephrine reuptake inhibitors (SNRIs)}

Both SSRIs (fluoxetine, sertraline, paroxetine, citalopram, escitalopram), and the newer SNRIs (venlafaxine, desvenlafaxine, duloxetine), are first-line, evidence-based treatments for depression in non-PD populations; however, it has been relatively difficult to establish their efficacy in DPD. Until recently, there was only limited evidence relating to one SSRI, paroxetine, and the data was equivocal across different studies. ${ }^{27,34,35}$ Moreover, there has been lingering concern that SSRIs could produce movement disorder symptoms on their own, exacerbating PD-related motor symptoms. ${ }^{39}$ However as experience with SSRIs in this population has increased, these concerns have lessened. ${ }^{40}$

In a randomized, placebo-controlled, double-blind study, 115 subjects with DPD were enrolled, providing substantial power compared to most, if not all, previous studies. ${ }^{32}$ Patients were followed for 12 weeks. Both paroxetine and venlafaxine XR significantly improved the symptoms associated with depression. Importantly neither drug worsened motor function, and both drugs were well tolerated. ${ }^{32}$ This study provides a solid evidence base for using the SSRI, paroxetine, as well as an alternative to this, the SNRI, venlafaxine. Both medications have potentially favorable side effect profiles for this population as well. Paroxetine can enhance sleep, which may be beneficial in patients with PD, where insomnia is common even in the absence of depression. For venlafaxine, historically, the most significant side effect has been modest increases in diastolic blood pressure. Again, given the frequency of dysautonomia in PD, a small increase in blood pressure is less of a concern than it may otherwise be, and could be potentially useful. This study provides welcome Class 1 evidence that these commonly used medications, both of which have safety profiles offering the considerable advantages of TCAs, are effective in DPD. Furthermore, this study also suggests that, although there remains the important question of whether there are fundamental differences in the physiology of depression in PD and the general population, DPD is treatable with conventionally used antidepressants. ${ }^{41}$

\section{Dopamine receptor agonist therapy}

The MDS guidelines noted that pramipexole, a dopamine (D2/D3/D4) agonist used for PD motor symptom treatment, has been shown to have effectiveness in reducing depressive symptoms in PD, and therefore deemed it "clinically useful" the only treatment so designated at the time of its review. ${ }^{31}$ In an uncontrolled comparison of pramipexole and sertraline (an SSRI), pramipexole showed promise in reducing depressive symptoms. ${ }^{42}$ In a larger randomized-controlled study, the effectiveness of pramipexole for reducing depressive symptoms was validated..$^{43}$ Of course, a benefit of pramipexole is that it is used to treat motor symptoms as well, and this dual purpose could make it a very attractive agent. At the same time, it should be noted that pramipexole use has risks, including that it can cause dyskinesia. Moreover, this drug also has the potential to trigger impulse control disorders such as increased gambling among psychiatrically vulnerable patients. ${ }^{44,45}$

Further study in larger, more varied populations of PD that more closely simulate clinical patient groups will help to strengthen the evidence for using pramipexole for DPD. Notably, the antidepressant effects were over and above the impact of pramipexole on improving movements. This raises an important issue in that it might be expected that improving the motor symptoms of PD may reduce depression. However, evidence suggests that just as PD does not inevitably produce depression, relieving movement impairment does not necessarily improve depression; in fact, most of the studies on depressive symptomatology incidence in PD have been conducted in pools of patients treated for their PD, not untreated controls.

\section{Other pharmacotherapy approaches for depression in Parkinson's disease Bupropion}

Bupropion is a well-established, effective antidepressant in otherwise healthy adults. Because its mechanism of action, 
through DA and norepineprhine (NE) systems, hypothetically rectifies some of the core neurophysiological deficits in PD, it has been suggested as a logical choice to use in DPD. ${ }^{46}$ However, there is not a strong evidence base for using it to treat DPD. It should also be noted that bupropion has the potential to lower the seizure threshold, which while not a specific concern in PD, it is useful to keep in mind in any neurodegenerative disease patient population.

\section{Mirtazapine}

Mirtazapine is a central alpha-2 adrenergic antagonist with effects on both NE and serotonergic systems, and its action on these systems might be expected to be beneficial in DPD. It is effective for depression and anxiety in healthy populations, and is frequently prescribed in geriatric populations where it is well-tolerated. In addition, it has a favorable side effect profile, reducing nausea, increasing appetite, and improving sleep - all things commonly troubling those with PD. As we have detailed, there is no Class 1 evidence supporting its use in this population if you assume that DPD represents a distinct population of those with depression who need to be approached differently than anyone else with a major depression.

\section{Atomoxetine}

Atomoxetine is a selective NE reuptake inhibitor most frequently used to treat attention deficit disorder. However, given that NE system degeneration is a major feature of PD, and given that it is also likely to contribute to depressive symptoms, interventions targeting NE may be useful to treat DPD. In an 8-week, randomized, placebo-controlled study, atomoxetine was not effective for depression and other neuropsychiatric symptoms in PD. ${ }^{47}$ However, in an analysis employing more liberal response criteria, there was a trend toward significance, which might have proven significant in a more highly powered study. In addition, there was improvement in global cognition and daytime sleepiness, both of which are common clinical concerns in PD. Although atomoxetine use for DPD cannot be empirically supported based on this study, it is possible that further trials may demonstrate its value for those with PD.

\section{Omega-3 fatty acids}

A double-blind, placebo-controlled study of 31 subjects found fish oil to be beneficial in people with major depression and PD. ${ }^{48}$ As omega-3 fatty acids are widely available dietary supplements with limited side effects, they may be a useful addition to treatment. However, given the very small size of the single study, this is an area that requires further investigation.

\section{Other agents for consideration}

While also less supported by data at this time, several other agents merit further study. Ropinirole has, to a limited extent, been shown to improve depressive and anxiety symptoms in PD. ${ }^{49,50}$ Monoamine oxidase inhibitors have been used for many years in the treatment of refractory or atypical depression. One monoamine oxidase inhibitor, selegiline, is already used to treat PD. Speculatively, although there is only limited evidence supporting its use as an antidepressant generally, ${ }^{51,52}$ it may prove useful in DPD where its effects may be more specifically targeting depression in PD. However, selegiline is not a first-line agent in PD, and may increase mortality overall in PD. ${ }^{53}$ Potential drug interactions are also a concern, particularly serotonin syndrome marked by elevated body temperature, hyperreflexia, and autonomic instability. ${ }^{54}$ At this point, it is not a principal treating agent for DPD, but rather a consideration in refractory DPD.

Beyond pharmacotherapy, there is support for including psychotherapy in treating DPD. An emerging literature suggests that cognitive behavioral therapy (CBT), an evidencebased psychotherapy shown to be effective in treating depression in otherwise healthy populations, is very likely to be effective in DPD.

\section{Psychotherapy for depression in Parkinson's disease}

As the title of this review suggests, we have only addressed the pharmacological treatment of depression in those suffering from PD. There is strong evidence (in the general population with depression, and in those with medical illnesses and depression) that psychotherapies are at least as effective as medication treatments for major depression. For instance, in those with major depression, CBT has been shown to be as effective as antidepressant treatment, with the combination of CBT and an antidepressant more effective than either treatment alone. ${ }^{55}$

CBT has been shown to work specifically in a PD population in a well-powered, randomized, and carefully controlled study. ${ }^{56}$ Moreover, in a smaller study, CBT was shown to be effective even in telephone-based treatments, which may be especially valuable in this population. ${ }^{57}$ In our view, the success of CBT in those with PD warrants our recommending it for patients early on in treatment. As is our approach with all depressed patients, we discuss both medication and psychotherapy treatments, and work to provide one or both of the treatments based on patient preference. 


\section{An integrated approach in the treatment of depression in Parkinson's disease}

In the United States and other developed countries, we are not at a loss for medications that are effective at treating depression. However, most people with major depression do not have it identified or treated. ${ }^{58}$ Those who do have it identified and treated are not typically treated in specialty mental health care settings. In the primary care setting, depression care as usual for those identified and treated is often not effective. ${ }^{59}$

While it seems likely that there are physiologic differences between individuals with PD and major depression and those with major depression in the unaffected general population, we anticipate that our current antidepressants will probably be effective for these patients. The major issue facing us, then, is the same as in the general population: doing a good job of identifying those with PD who are depressed, and effectively providing treatment in a primary care, a neurology clinic, or in a specialty mental health setting. We know that simply implementing screening programs in a clinic is not useful unless there is an effective system of care to which the patient can be referred. ${ }^{60}$ This is where "collaborative" or "integrated" models of care have filled a massive health services gap and are proving very helpful for patients being seen outside of specialty mental health care settings. ${ }^{61}$ These models of depression care have been shown to be more effective than care as usual when comparing short- and long-term outcomes. ${ }^{62}$

\section{Active ingredients of integrated care}

"Integrated" or "collaborative" care for depression treatment refers to a large number of complex interventions. The description of a large randomized trial of collaborative care for depression in older primary care patients (Improving Mood Promoting Access to Collaborative Treatment) will help readers begin to appreciate what is typically meant when "evidence-based" integrated treatment programs are described. ${ }^{63}$ There are two key elements to integrated depression care: ${ }^{64}$

1. Systematic care management by a trained therapist, nurse, or social worker. The care manager is in the treatment setting where the patient receives most care and provides the following:

a. An initial evaluation after a depressed person has been identified through some screening mechanism.

b. Support to the patient and primary provider around medication treatment.

c. A brief, evidence-based psychotherapy such as CBT. d. Close monitoring and follow up to facilitate timely treatment modifications.

2. Frequent (eg, weekly) consultation between the care manager, a psychiatrist, and the primary provider (be it a primary care doctor or a neurologist).

Building on this description, we will now describe a hypothetical integrated care model for those with depression and PD.

\section{Collaborating to care for depression in Parkinson's disease (a hypothetical care model)}

- All patients with PD are screened in a clinic using the GDS-15 (discussed above), or the Patient Health Questionnaire-9 (a self-report depression screening tool that has been empirically validated in numerous medical populations). ${ }^{66,67}$

- Anyone screening positive is referred to a "care manager"-a clinical nurse, therapist, or social worker who is familiar and comfortable with these patients and problems.

- The care manager completes a detailed psychosocial evaluation.

- The care manager consults with a psychiatrist weekly (in person or on the phone) to discuss new evaluations and follow-ups. The consulting psychiatrist (preferably a consultation-liaison psychiatrist with skill and comfort in managing those with PD) supports diagnostic decision making and provides the treating neurologist or primary care doctor with medication recommendations.

- The care manager follows up with the patient weekly (in person or over the phone), provides brief, evidence-based psychotherapy (eg, CBT), and uses a tool such as the GDS-15 or the Patient Health Questionnaire-9 to monitor symptoms and treatment.

- During the weekly consultation with the psychiatrist, decisions are made about medication titration or changes. In cases where there is no improvement or the diagnosis is not clear, the psychiatrist evaluates the patient in person to better support depression care in the setting where most other care is received (not in a specialty mental health clinic).

- Results of the tools and treatment course are kept in a registry that facilitates follow-up and consultation.

The limitations and challenges of doing this are numerous and are not addressed here, but this should be food for thought given the scope of the problem of DPD, the evidence base supporting these models of care, and the resource limitations in psychiatry. For those interested in learning more 
about the translation of these models of care into real-world treatment environments (eg, receiving training), please visit the University of Washington's Advancing Integrated Mental Health Solutions website. ${ }^{65}$

\section{Disclosure}

The authors report no conflicts of interest in this work. While both authors have University of Washington affiliations, neither receives any funding from the UW AIMS center.

\section{References}

1. Lees AJ, Hardy J, Revesz T. Parkinson's disease. Lancet. 2009; 373(9680):2055-2066.

2. Aarsland D, Påhlhagen S, Ballard CG, Ehrt U, Svenningsson P. Depression in Parkinson disease - epidemiology, mechanisms and management. Nat Rev Neurol. 2011;8(1):35-47.

3. Reijnders JS, Ehrt U, Weber WE, Aarsland D, Leentjens AF. A systematic review of prevalence studies of depression in Parkinson's disease. Mov Disord. 2008;23(2):183-189; quiz 313.

4. Slaughter JR, Slaughter KA, Nichols D, Holmes SE, Martens MP. Prevalence, clinical manifestations, etiology, and treatment of depression in Parkinson's disease. J Neuropsychiatry Clin Neurosci. 2001;13(2):187-196.

5. Improving Chronic Illness Care. The Chronic Care Model [webpage on the Internet]. Seattle, WA: Improving Chronic Illness Care. Available from: http://www.improvingchroniccare.org/index.php? $\mathrm{p}=$ The_ Chronic_Care_Model\&s=2. Accessed August 1, 2012.

6. American Psychiatric Association. Diagnostic and Statistical Manual of Mental Disorders DSM-IV-TR, Fourth Edition, Text Revision. 4th ed. Washington, DC: American Psychiatric Association; 2000.

7. Weintraub D, Moberg PJ, Duda JE, Katz IR, Stern MB. Effect of psychiatric and other nonmotor symptoms on disability in Parkinson's disease. J Am Geriatr Soc. 2004;52(5):784-788.

8. Kuopio AM, Marttila RJ, Helenius H, Toivonen M, Rinne UK. The quality of life in Parkinson's disease. Mov Disord. 2000;15(2):216-223.

9. Aarsland D, Brønnick K, Ehrt U, et al. Neuropsychiatric symptoms in patients with Parkinson's disease and dementia: frequency, profile and associated care giver stress. J Neurol Neurosurg Psychiatry. 2007;78(1): $36-42$.

10. Schrag A. Psychiatric aspects of Parkinson's disease - an update. J Neurol. 2004;251(7):795-804.

11. Global Parkinson's Disease Survey Steering Committee. Factors impacting on quality of life in Parkinson's disease: results from an international survey. Mov Disord. 2002;17(1):60-67.

12. Knipe MD, Wickremaratchi MM, Wyatt-Haines E, Morris HR, Ben-Shlomo Y. Quality of life in young- compared with late-onset Parkinson's disease. Mov Disord. 2011;26(11):2011-2018.

13. Kasten M, Kertelge L, Tadic V, et al. Depression and quality of life in monogenic compared to idiopathic, early-onset Parkinson's disease. Mov Disord. 2012;27(6):754-759.

14. Schrag A, Hovris A, Morley D, Quinn N, Jahanshahi M. Caregiverburden in parkinson's disease is closely associated with psychiatric symptoms, falls, and disability. Parkinsonism Relat Disord. 2006;12(1): 35-41.

15. Kummer A, Cardoso F, Teixeira AL. Suicidal ideation in Parkinson's disease. CNS Spectr. 2009;14(8):431-436.

16. Marsh L, McDonald WM, Cummings J, Ravina B; for NINDS/ NIMH Work Group on Depression and Parkinson's Disease. Provisional diagnostic criteria for depression in Parkinson's disease: report of an NINDS/NIMH Work Group. Mov Disord. 2006;21(2): $148-158$.

17. Schrag A, Leentjens AF. Parkinson disease: Scales to detect depression in Parkinson disease. Nat Rev Neurol. 2012;8(7):359-360.
18. Cimino CR, Siders CA, Zesiewicz TA. Depressive symptoms in Parkinson disease: degree of association and rate of agreement of clinician-based and self-report measures. J Geriatr Psychiatry Neurol. 2011;24(4):199-205.

19. Schrag A, Barone P, Brown RG, et al. Depression rating scales in Parkinson's disease: critique and recommendations. Mov Disord. 2007;22(8):1077-1092.

20. Yesavage JA, Brink TL, Rose TL, et al. Development and validation of a geriatric depression screening scale: a preliminary report. J Psychiatr Res. 1982-1983;17(1):37-49.

21. Williams JR, Hirsch ES, Anderson K, et al. A comparison of nine scales to detect depression in Parkinson disease: which scale to use? Neurology. 2012;78(13):998-1006.

22. McDonald WM, Holtzheimer PE, Haber M, Vitek JL, McWhorter K, Delong M. Validity of the 30-item geriatric depression scale in patients with Parkinson's disease. Mov Disord. 2006;21(10):1618-1622.

23. Thompson AW, Liu H, Hays RD, et al. Diagnostic accuracy and agreement across three depression assessment measures for Parkinson's disease. Parkinsonism Relat Disord. 2011;17(1):40-45.

24. Richard IH, Kurlan R. A survey of antidepressant drug use in Parkinson's disease. Parkinson Study Group. Neurology. 1997;49(4): 1168-1170.

25. Shabnam GN, Chung TH, Kho D, Richards HE, Ce C. Therapies for depression in Parkinson's disease. Cochrane Database Syst Rev. 2003:2.

26. Andersen J, Aabro E, Gulmann N, Hjelmsted A, Pedersen HE. Anti-depressive treatment in Parkinson's disease. A controlled trial of the effect of nortriptyline in patients with Parkinson's disease treated with L-DOPA. Acta Neurol Scand. 1980;62(4):210-219.

27. Wermuth L, Sørensen PS, Timm S, et al. Depression in idiopathic Parkinson's disease treated with citalopram: a placebo-controlled trial. Nord J Psychiatry. 1998;52(2):163-169.

28. Rabey JM, Orlov E, Korczyn AD. Comparison of fluvoxamine versus amitryptyline for treatment of depression in Parkinson's disease. Neurology. 1996;46:A374.

29. Miyasaki JM, Shannon K, Voon V, et al; for Quality Standards Subcommittee of the American Academy of Neurology. Practice Parameter: evaluation and treatment of depression, psychosis, and dementia in Parkinson disease (an evidence-based review): report of the Quality Standards Subcommittee of the American Academy of Neurology. Neurology. 2006;66(7):996-1002.

30. Skapinakis P, Bakola E, Salanti G, Lewis G, Kyritsis AP, Mavreas V. Efficacy and acceptability of selective serotonin reuptake inhibitors for the treatment of depression in Parkinson's disease: a systematic review and meta-analysis of randomized controlled trials. BMC Neurol. 2010;10:49.

31. Seppi K, Weintraub D, Coelho M, et al. The Movement Disorder Society Evidence-Based Medicine Review Update: Treatments for the nonmotor symptoms of Parkinson's disease. Mov Disord. 2011; 26 Suppl 3: S42-S80.

32. Richard IH, McDermott MP, Kurlan R, et al; for SAD-PD Study Group. A randomized, double-blind, placebo-controlled trial of antidepressants in Parkinson disease. Neurology. 2012;78(16):1229-1236.

33. Menza M, Dobkin RD, Marin H, et al. A controlled trial of antidepressants in patients with Parkinson disease and depression. Neurology. 2009;72(10):886-892.

34. Barone P, Scarzella L, Marconi R, et al. Pramipexole versus sertraline in the treatment of depression in Parkinson's disease. J Neurol. 2006;253:601-607.

35. Ceravolo R, Nuti A, Piccinni A, et al. Paroxetine in Parkinson's disease. Neurology. 2000:55:1216-1218.

36. Devos D, Dujardin K, Poirot I, et al. Comparison of desipramine and citalopram treatments for depression in Parkinson's disease: a double-blind, randomized, placebo-controlled study. Mov Disord. 2008;23(6):850-857.

37. Okun MS, Fernandez HH. Will tricyclic antidepressants make a comeback for depressed Parkinson disease patients? Neurology. 2009;72(10):868-869. 
38. Paumier KL, Siderowf AD, Auinger P, et al; for Parkinson Study Group Genetics Epidemiology Working Group. Tricyclic antidepressants delay the need for dopaminergic therapy in early Parkinson's disease. Mov Disord. 2012;27(7):880-887.

39. Richard IH, Maughn A, Kurlan R. Do serotonin reuptake inhibitor antidepressants worsen Parkinson's disease? A retrospective case series. Mov Disord. 1999;14(1):155-157.

40. Dell'Agnello G, Ceravolo R, Nuti A, et al. SSRIs do not worsen Parkinson's disease: evidence from an open-label, prospective study. Clin Neuropharmacol. 2001;24(4):221-227.

41. Perez-Lloret S, Rascol O. Parkinson disease: Serotonin reuptake inhibitors for depression in PD. Nat Rev Neurol. 2012;8(7):365-366.

42. Barone P, Scarzella L, Marconi R, et al; for Depression/Parkinson Italian Study Group. Pramipexole versus sertraline in the treatment of depression in Parkinson's disease: a national multicenter parallel-group randomized study. J Neurol. 2006;253(5):601-607.

43. Barone P, Poewe W, Albrecht S, et al. Pramipexole for the treatment of depressive symptoms in patients with Parkinson's disease: a randomised, double-blind, placebo-controlled trial. Lancet Neurol. 2010;9(6):573-580.

44. Bostwick JM, Hecksel KA, Stevens SR, Bower JH, Ahlskog JE. Frequency of new-onset pathologic compulsive gambling or hypersexuality after drug treatment of idiopathic Parkinson disease. Mayo Clin Proc. 2009;84(4):310-316.

45. Dodd ML, Klos KJ, Bower JH, Geda YE, Josephs KA, Ahlskog JE. Pathological gambling caused by drugs used to treat Parkinson disease. Arch Neurol. 2005;62(9):1377-1381.

46. Raskin S, Durst R. Bupropion as the treatment of choice in depression associated with Parkinson's disease and it's various treatments. Med Hypotheses. 2010;75(6):544-546.

47. Weintraub D, Mavandadi S, Mamikonyan E, et al. Atomoxetine for depression and other neuropsychiatric symptoms in Parkinson disease. Neurology. 2010;75(5):448-455.

48. da Silva TM, Munhoz RP, Alvarez C, et al. Depression in Parkinson's disease: a double-blind, randomized, placebo-controlled pilot study of omega-3 fatty-acid supplementation. J Affect Disord. 2008;111(2-3): 351-359.

49. Rektorova I, Balaz M, Svatova J, et al. Effects of ropinirole on nonmotor symptoms of Parkinson disease: a prospective multicenter study. Clin Neuropharmacol. 2008;31(5):261-266.

50. Pahwa R, Stacy MA, Factor SA, et al; for EASE-PD Adjunct Study Investigators. Ropinirole 24-hour prolonged release: randomized, controlled study in advanced Parkinson disease. Neurology. 2007; 68(14):1108-1115.

51. Amsterdam JD. A double-blind, placebo-controlled trial of the safety and efficacy of selegiline transdermal system without dietary restrictions in patients with major depressive disorder. J Clin Psychiatry. 2003; 64(2):208-214.

52. Feiger AD, Rickels K, Rynn MA, Zimbroff DL, Robinson DS. Selegiline transdermal system for the treatment of major depressive disorder: an 8-week, double-blind, placebo-controlled, flexible-dose titration trial. J Clin Psychiatry. 2006;67(9):1354-1361.
53. Vu TC, Nutt JG, Holford NH. Disease progress and response to treatment as predictors of survival, disability, cognitive impairment and depression in Parkinson's disease. Br J Clin Pharmacol. 2012;74(2):284-295.

54. Richard IH, Kurlan R, Tanner C, et al. Serotonin syndrome and the combined use of deprenyl and an antidepressant in Parkinson's disease. Parkinson Study Group. Neurology. 1997;48(4):1070-1077.

55. Sudak DM. Cognitive behavioral therapy for depression. Psychiatr Clin North Am. 2012;35(1):99-110.

56. Dobkin RD, Menza M, Allen LA, et al. Cognitive-behavioral therapy for depression in Parkinson's disease: a randomized, controlled trial. Am J Psychiatry. 2011;168(10):1066-1074.

57. Dobkin RD, Menza M, Allen LA, et al. Telephone-based cognitivebehavioral therapy for depression in Parkinson disease. J Geriatr Psychiatry Neurol. 2011;24(4):206-214.

58. Kessler RC, Demler O, Frank RG, et al. Prevalence and treatment of mental disorders, 1990 to 2003. N Engl J Med. 2005;352(24):2515-2523.

59. Katon W, von Korff M, Lin E, Bush T, Ormel J. Adequacy and duration of antidepressant treatment in primary care. Med Care. 1992;30(1):67-76.

60. Gilbody S, House AO, Sheldon TA. Screening and case finding instruments for depression. Cochrane Database Syst Rev. 2005;(4): CD002792.

61. Unützer J, Katon W, Callahan CM, et al; for IMPACT Investigators. Improving Mood-Promoting Access to Collaborative Treatment. Collaborative care management of late-life depression in the primary care setting: a randomized controlled trial. JAMA. 2002;288(22): 2836-2845.

62. Gilbody S, Bower P, Fletcher J, Richards D, Sutton AJ. Collaborative care for depression: a cumulative meta-analysis and review of longerterm outcomes. Arch Intern Med. 2006;166(21):2314-2321.

63. Unützer J, Katon W, Williams JW Jr, et al. Improving primary care for depression in late life: the design of a multicenter randomized trial. Med Care. 2001;39(8):785-799.

64. Unützer J, Schoenbaum M, Druss BG, Katon WJ. Transforming mental health care at the interface with general medicine: report for the presidents commission. Psychiatr Serv. 2006;57(1):37-47.

65. University of Washington Advancing Integrated Mental Health Solutions [homepage on the internet]. Seattle: University of Washington Department of Psychiatry and Behavioral Sciences. Available from: http://uwaims.org/. Accessed December 1, 2012.

66. Kroenke K, Spitzer RL, Williams JB. The PHQ-9: validity of a brief depression severity measure. J Gen Intern Med. 2001;16(9):606-613.

67. Spitzer RL, Kroenke K, Williams JB. Validation and utility of a selfreport version of PRIME-MD: the PHQ primary care study. Primary Care Evaluation of Mental Disorders. Patient Health Questionnaire. JAMA. 1999;282(18):1737-1744.
Degenerative Neurological and Neuromuscular Disease

\section{Publish your work in this journal}

Degenerative Neurological and Neuromuscular Disease is an international, peer-reviewed, open access journal focusing on research into degenerative neurological and neuromuscular disease, identification of therapeutic targets and the optimal use of preventative and integrated treatment interventions to achieve improved outcomes, enhanced

\section{Dovepress}

survival and quality of life for the patient. The manuscript management system is completely online and includes a very quick and fair peer-review system. Visit http://www.dovepress.com/testimonials.php to read real quotes from published authors. 